\title{
Ruang Publik dan Modal Sosial: Privatisasi dan Komodifikasi Ruang di Kampung
}

\author{
Bobi B. Setiawan
}

This article describes that village is understood as a form of comunal housing, and there is a public space. It is needed the public intervension in keeping and developing the existence of public space in villages in indonesia. The forms of intervension is suggested. But, it is important to note that the public space in villages in Indonesia can be developed by management process based on the village communities. The public space and social capital are interrelated each other- the public space prepares to support social capital, and the existence of public space needs one grade of certain social capital.

Key words: Kampung, Informal Settlement, Indonesia

\section{Ruang Publik dan Modal Sosial}

Selama ini, diskusi tentang ruang publik - didefinisikan secara umum sebagai ruang yang dapat diakses dan dimanfaatkan oleh warga kota - telah banyak dilakukan. Fokus diskusi umumnya ditekankan pada upaya-upaya untuk menjelaskan manfaat ruang publik bagi lingkungan fisik kota. Diskusi tentang ruang publik pada umumnya juga dicampur-adukkan dengan ruang terbuka secara umum, khususnya ruang terbuka hijau. Ruang publik, dengan demikian lebih dipersepsikan sebagai satu elemen penting dari estetika kota. Dalam konteks desain kota, diskusi ruang publik dengan demikian mengarah pada debatdebat tentang bagaimana merancang ruang publik yang indah dan estetis. Sangat jarang didiskusikan kaitan antara ruang publik dan modal sosial, khususnya masyarakat kota.

Modal sosial atau social capital merupakan satu terminologi baru yang dikembangkan oleh ahli-ahli sosial untuk memperkaya pemahaman kita tentang masyarakat dan komunitas. Modal sosial menjadi khasanah perdebatan yang menarik bagi ahli-ahli sosial dan pembangunan khususnya awal tahun 1990an. Diskusi tentang modal sosial ini berawal dari realitas bahwa proses-proses pembangunan yang selama ini dilakukan di negara-negara berkembang diangga terlalu materialistik dan mengkesampingkan aspek-aspek sosial dan kultur (Coleman 
1990, Putnam 1995, Lesser 2000, Dasgupta dan Serageidin, 2000).

Sebagaimana didefinisikan oleh Putnam (1995) modal sosial adaiah "features of social organization such as networks, norms, and social trust that facilitate coordination and cooperation for mutual benefit." Dalam penjelasan ini, Putnam menekankan bahwa modal sosial merupakan pemahaman dan pengetahuan yang dimiliki bersama oleh komunitas, serta pola hubungan yan memungkinkan sekelompok individu melakukan satu kegiatan yang produktif. Terminologi ini merujuk pada organisasiorganisasi, struktur, dan hubunganhubungan sosial yang dibangun sendiri oleh komunitas, terlepas dari intervensi pemerintah atau pihak lain.

Coleman (1990) mengatakan bahwa modal sosial adalah "consist of some aspect of social structure, and they facilitate certain actions of individuals who are within the structure, Like other forms of capital, social capital is productice, making possible the achievement of certain ends that would not be attained is its absence." Dalam penjelasannyatersebut, Colemanmenegaskan mengenai pentingnya aspek produktivitas dalam modal sosial. Coleman mengatakan bahwa modal sosial diperlukan untuk mewujudkan tujuan tujuan yang tidak mungkin dapat dicapai secara individual. Coleman juga menekankan bahwa modal sosial mempunyai kontribusi yang penting bagi pengkuatan komunitas yang dibangun atas. dasar kesatuan pemahaman, kepercayaan, dan solidaritas antar individu.

-Modal sosial hanya dapat dibangun ketika tiap individu belajar dan mau mempercayai individu lain sehingga mereka mau membuat komitmen yang dapat dipertanggungjawabkan untuk mengembangkan bentuk-bentuk hubungan yang saling menguntungkan (Putman, 1995).
Menurut Lesser (2000), modal sosial sangat penting bagi komunitas karena: (1) mempermudah akses informasi bagi angota komunitas; (2) menjadi media power sharing atau pembagian kekuasaan dalam komunitas; (3) mengembangkan solidaritas; (4) memungkinkan mobilisasi sumber daya komunitas; (5) memungkinkan pencapaian bersama; dan (6) membentuk perilaku kebersamaam dan berorganisasi komunitas.

Perspektif tentang hubungan ruang dan sistem sosial itu sendiri mengalami perkembangan yang dinamik. Setelah model-model 'environmental determinism' dikrititik dan dikoreksi sebagai satu pendekatan yang kurang sempurna, ahli-ahli lingkungan perilaku dan psikologi semakin meyakini proses hubungan yang lebih dinamik (Rapoport, 1977, 1982). Kelompokkelompok ahli lingkungan dan perilaku mengembangkan berbagai model yang pada dasarnya melihat proses hubungan antara lingkungan dan perilaku yang timbal balik dan dialektik. Lingkungan dapatmempengaruhi perilaku, pada saat yang sama, perilaku dapat melakukan berbagai adaptasi untukmengubah dan mengembangkan lingkungannya agar sesuai atau akomodatip terhadap perilaku mereka.

Di Indonesia, kajian hubungan antara lingkungan dan perilaku ini berkembang sejak awal tahun 1990. Beberapa penelitian telah dilakukan dan menunjukkan dinamika hubungan yang menarik dan dialektik. Penelitian oleh Haryadi (1989), Setiawan dkk (1998), Saragih (1990) menunjukkan bahwa di lingkungan kampung padat kota, hubungan tersebut sangat kompleks. Haryadi (1989) sebagai misal menunjukkan húbungan yang dialektik antara tekanan sosial dan pola ruang di kampung pusat kota. Dia memperlihatkan betapa masyarakat kampung secara dinamik melakukan adaptasi perilaku dan juga 
lingkungan untuk merespon tekanan eksternal terhadap kampung. Berbagai penelitian ini menunjukkan bahwa di perkampungan kota di Indonesia, terjadi hubungan yang kompleks dan dinamik dimana komunitas kampung terus melakukan upaya-upaya adaptasi baik lingkungan dan perilakunya agar mereka tetap survive tinggal di kampung. Sejalan dengan perkembangan waktu, akan tetapi, terjadi proses-proses percepatan dan peningkatan kapital di lingkungan perkotaan dan kampung yang semakin menimbulkan tekanan dan persoalan bagi penduduk kampung untuk melakukan adaptasi terhadap perilaku dan lingkungannya.

\section{Privatisasi dan Kapitalisasi Kota}

Debat tentang kapitalisasi dan privatisasi kota sebenarnya telah lama berkembang. Pada tahun 1970an, dengan kesadaran kritis terhadap proses-proses kapitalisasi kota, beberapa ahli perkotaan mencoba menyoroti seraca kritis kecenderungan kapitalisasi kota yang berkelebihan serta menyodorkan berbagai pemikiran baru tentang bagaimana kota seharusnya dikembangkan (Parker, 2004). Sebagaimana ditunjukkan dengan beberapa karya tulisan dari Manuel Castells (1972, 1977,1989 ), dia mengkritisi perkembangan kota melalui kacamata marxis dan mengkhawatrikan proses-proses materialisasi pembangunan perkotaan yang cenderung menciptakan dual sosiety yang gapnya cialam. Karya David Harvey, dalam "The Condition of Postmodernity" (1989) juga menunjukkan pemikiran yang sangat kritis terhadap proses kapitalisasi kota. Dia mengingatkan bahwa proses kapitalisasi kota menunjukkan proses dimana kota merupakan tempat untuk mereproduksi kapital dan kekuasaan, yang apabila dibiarkan tak terkontrol dapat menimbulkan revolusi sosial yang negatip.

Dalam perkembangannya, pemikiranpemikiran kritis tentang proses kapitalisasi dan materialisasi kota, mengarah pada ideide normatip tentang bagaimana kota seharusnya. Daläm konteks ini, karya-karya Jane Jacobs $(1986,1992)$ merupakan karya yang jadi referensi utama tentang bagaimana kota seharusnya. Ide-ide Jane Jacobs tentang kota yang liveable mendapat perhatian penuh dari para alhi dan praktisi kota. Dalam bukunya The Death and Life of Great American Cities, Jacobs menyarankan beberapa prinsip dasar perancangan kota yang livable dan bertumpu pada skala manusia (1992).

Tidak hanya pemikiran-pemikiran normatip tentang betuk kota seharusnya, banyak ahli kemudian juga menekănkan tentang pentingnya dinamika penduduk kota, khususnya mereka yang selama ini tidak diperhatikan dalam proses-proses perencanaan kota. Friedmann, dalam buku terbarunya "the Prospects of the Cities" secara kritis menengarai tentang berkembangnya kelompok-kelompok lokal yang aktip dalam gerakan sosial atau apa yang ia sebut sebagai insurgent citizenship. Friedmann mengingatkan tentang pentingnya memperhatikan kelompokkelompok tersebut dalam perencanaan, dan bahkan mendukung mereka agar menjadi komunitas yang aktip dalam politik perkotaan, baik pada tataran diskursus maupun pratek. Dengan kata lain, ia menyarankan bahwa perencana harus mendukung terwujudnya kota sebagai wadah yang kondusip untuk membuka ruang-ruang demokrasi. Dengan kata lain, Friedmannmengingatkan kita pada hak-hak atas ruang kehidupan penduduk kota, khususnya yang selama ini justru miskin, lemah, dan tidak 
berdaya - Friedmann mengatakannya sebagai " the right to the city."

Pada akhirnya, krtitik terhadap prosesproses kapitalisasi kota bermuara pada ideide untuk terus menghadirkan sisi kemanusiaan kota, juga pentingnya memperhatikan komunitas-komunitas kota: Dalam Bukunya 'The Spirit of Community' Amitai Etzioni (1993) mengkritisi proses perkembangan peradaban di Amerika yang kurang memperhatikan eksistensi komunitaș-komunitas. Etzioni menyarankan mengenai perlunya dibangun kembali spirit komunitas sebagai basis pembangunan di masa depan. Sementara itu, Friedmann menyoroti secara khusus mengenai kebutuhan untuk menghadirkan kota yang "human flourishing." Human flourishing hanya akan terjadi bila kita dapat menjamin kehidupan warga yang dinamis dan bebas dari kontrol, tekanan, dan kekuatan negara maupun kapital. la menyebutnya dengan istilah "Multipli/city," satu kondisi kehidupan dan spirit warga yang dinamis, dimana hakhak dasar mereka akan waktu, ruang, pekerjaan, dan sumber daya kota terjamin.

Melihat secara kritis, perkembangan kota-kota di Indonesia, kita harus secara kritis mempertanyakan ke arah mana kota kota kita akan dikembangkan. Yang jelas telah terjadi saat ini adalah proses-proses kapitalisasi dan materialisasi kota yang berlebihan dan seakan-akan tidak terkontrol. Proses-proses perkembangn kota di Indonesia telah sepenuhnya dikendalikan oleh pasar dan kapital. Ruang-ruang sosial dan kultural kota-kota kita telah terancam, sementara pemerintah kota tidak mampu melakukan intervensi untuk mengontrol dan mengkoreksi eksternalitas pasar yan negatip. Hasilnya adalah satu proses 'dehumanisasi' kota yang, semakin mengkhawatirkan.

\section{Privatisasi dan Komodifikasi Ruang Publik di Kampung}

Kampung, sebagai satu fenomena khas perkotaan di Indonesia, mendapatkan perhatian yang naik dan turun. Kadangkala, banyak perhatian, baik dari para ahli maupun praktisi terhadap kampung, kala lain, kampung dilupakan dan tidakmendapat perhatian yang seharusnya. Kenyataan menunjukkan bahwa sebagian besar penduduk perkotaan Indonesia tinggal dan menggantungkan hidupnya di kampungkampung. Sementara itu, tidak boleh dilupakan bahwa kampung juga mendominasi karakter fisik-penampakan lingkungan kota di Indonesia.

Kampung sebagai satu bentuk permukiman yang 'organik' dan 'informal' menjadi khas karena keragaman wujud fisiknya. Justru karena proses pertumbuhannya yang 'organik' tiap kampung mempunyai wujud yang berbeda dan khas. Tiap kampung menjadi satu 'kolase' artefak tersendiri yang merefleksikan 'kecerdikan' komunitas kampung untuk mensiasati keterbatasan ruang yang ada. Dengan keterbatasan ruang yang ada penduduk kampung selama ini 'berhasil' mensiasati secara cerdik kebutuhan ruang, baik untuk kebutuhan privat maupun sosial. Setiap jengkal ruang dimanfaatkan secara optimal, dan ini semua menghadrikan kampung sbegai satu ruang kehidupan yang 'livable.' Meskipun seringkali dicirikan dengan keterbatasan infrastruktur sehingga kampung seringkali 'dikonotasikan' sebagai pemukiman kumuh, kampung merupakan solusi yang optimum persoalan perumahan di Indonesia.Di kampunglah berbagai kebutuhan perumahan di Indonesia diwadahi, khususnya bagi kelompok menengah ke bawah. 
Secara sosial dan ekonomi, kampung juga merupakan fenomena yang meṇarik karena kebergaman corak sosial dan. ekonominya. Secara sosial, kämpung selalu dicirikan sebagai komunitas dengan tingkat 'kebersamaan' yang istimewa. Gotong royong dan berbagai bentuk kebersamaan lain hidup secara dinamik di kampung. DI kampung pula di temui berbagai bentuk kegiatan ekonomi yang beragam, sebagai perwujudan komunitas kampung untuk 'survive.' Kampung, derigan demikian, bukan hanya tempat 'hunian' semata, melainkan juga tempatkehidupan yang sesunguhnya (Guiness 1987, Sullivan 1992, Setiawan, 1995, 1998).

Dalam perkembangannya, akan tetapi, banyak kampung yang mengalami proses transisi yang dinamik. Terutama pada. kampung-kampung yang terletak di pusatpusat perekonomian kota, tekanan ekonomi dan penduduk yang demikian besar memaksa kampung melakukan prosesproses perubahan yang tidak selalu sejalan dengan karakter kampung yang digambarkan sebelumnya. Keadaan ini dipicu dengan krisis ekonomi yang terjadi sejak tahun 1997, yang membuat penduduk kampung semakin tertekan secara ekonomi. Tekanan ekonomi penduduk kampung ini memaksa mereka untuk semakin memberdayakan berbagai bentuk 'äset' yang mereka miliki agar dapat terus 'survive' termasuk aset fisik mereka yakni ruang.

Lebih lanjut, tekanan ekonomi dan sosial yang semakin tinggi ternyata juga dapat menggoyahkan sendi-sendi sosial kehidupan kampung. Sebagaimana didokumentasikan oleh Setiawan (2000) terjadi kecenderungan memudamya bentuk-bentuk 'kebersamaan' sosial di kampung. Tekanan ekonomi yang tinggi memaksa tiap individu di kampung untuk melakukan berbagai bentuk 'survival strategy' yang kadangkala tidak sejalan dengan kesepakatankesepakatan sosial sebelumnya. Terjadi pula kecenderungan dimana tiap warga kampung semakin tidak mempunyai waktu luang untuk aktivitas-aktivitas sosial kampung, bahkan hal ini dialami oleh pengurus-pengurus kampung. Dengan kata lain, tekanan ekonomi yang besar menekan pula eksistensi dan kinerja institusi, pranata, dan praktek-praktek sosial di kampung. Modal sosial kampung, cenderung mengalami perubahan dan pelemahan.

Implikasi sekaligus representasi dari tererosinya modal sosial karena tekanan ekonomi di kampung tersebut antara lain diwujudkan dengan proses-proses privatisasi dan komersialisasi ruang sebagaimana akan dijelaskan berikut ini.

\section{Peningkatan Kepadatan Bangunan}

Secara umum, hampir sebagian besar kampung mengalami peningkatan kepadatan bangunan yang sangat signifikan dan cenderung mendekati batas-batas yang mengkhawatirkan. Perkampungan di sepanjang sungai Code, sebagai misal, mengalami peningkatan kepadatan bangunan yang cukup signifikan sejak dua dekade lalu. Sekitar tahun 1980, tingkat KDB kampungkampung di sepanjang sungai Code adalah $60 \%$, sekarang KDB ini telah mencapai $70-$ $80 \%$ (Setiawan, 1987, 1995, 1998, 2002, Zaim, 2004). Peningkatan KDB kampung secara umum ini terjadi baik karena perluasan bangunan pribadi, maupun okupasi ruangruang umum yang ada untuk berbagai peruntukan. Perlu dicatat disini bahwa peningkatan kepadatan bangunan ini juga disertai peningkatan kepadatan hunian, yang dikhawatirkan dapat mengarah terjadinya 'over crowding' dengan segala implikasinya termasuk kemungkinan 'stress.' 


\section{Ekspansi Bangunan Privat pada Jalan Kampung/gang}

Bentuk lain proses privatisasi dan komersialisasi ruang di kampung adalah ekspansi bangunan privat khususnya pada jalan-jalan atau gang-gang di kampung. Sebagaimana telah didokumentasikan oleh Indartoro(1992) wujud fisik kampung-kampung di antara lain ditunjukkan dengan perwujudan gang-gang dalam kampung. Jalan atau ganggang ini disebutsebagai 'jalan rukunan' karena merupakan perwujudan dari bentuk kerukunan warga kampung yang 'mendermakan' sebagian tanahnya untuk kepentingan jalan yang notabene kepentingan umum. Tekanan ekonomi yang tinggi, akan tetapi, memaksa banyak warga kampung 'memperluas' pernanfaatan 'aset' mereka untukkepentingan privat: Yang terjadi adalah pengingkaran atau pengurangan terhadap kontribusi sosial mereka yakni dengan memperluas ruang privatnya pada gang-gang kampung sehingga menjadi semakin sempit. Terdapat kecenderungan beberapa gang yang karena begitu sempitnya tidak lagi dapat dipakai atau sulit dipakai untuk dilewati 'keranda' - satu bentuk standard lebar minimum gang yang selama ini dipakai secara umum oleh warga . kampung. Perlu dicatat disini bahwa 'penciutan' gang-gang kampung ini cukup mengkhawatirkan terutama karena menjadikan kampung lebih rentan terhadap bahaya kebakaran.

\section{Pemanfaatan Ruang Publik untuk Kepentingan Privat}

Bentuk lain privatisasi ruang di kampung adalah okupasinang-ruang publikatau ruangruang yang selama ini terlantar. Contohnya adalah okupasi bantaran sungai, okupasi di sepanjang selokan atau bahkan di atas selokan, okupasi ruang hijau, okupasi lapangan olah raga, dan okupasi ruang-ruang terlantar/sisa. Proses ini cukup mengkhawatrikan terjadi karena menunjukkan juga kelemahan institusi dan pranata sosial warga kampunguntukmencegah terjadinya proses okupasi tersebut.

\section{Pemanfaatan Bangunan untuk Kepentingan Komersial}

Kecenderungan lain yang terjadi adalah peningkatan pemanfaatan bangunan pribadidan umumuntukkegiatan usaha. Tekanan ekonomi yang ada, memaksa warga kampung untuk memperluas dan meningkatkan kegiatan ekonomi rumah tangga dalam bentuk 'homebased enterprises.' Wujud 'home-based enterprises' ini beragam, mulai dari pemanfaatan rumah untuk warung, usaha kost-kostan, pembuatan makanan, kerajinan, dan usahajasa lain (Marsoyo, 1993; Naareswati, 1997). Di Kampung Ratmakan, telah terjadi pengurangan areauntukperumahan, dari $84 \%$ ditahun 1969 , menjadi $34 \%$ di tahun 1985 , dan hanya $29 \%$ di tahun 2003 (Zaim, 2004). Perubahan inj tentunya merupakan gejala yang wajar dan positip secara ekonomi, akan tetapi apabila tidak dikontrol dapat mengancam sistem kehidupan dan lingkungan warga kampung. Tidak saja ruang kehidupan untuk kegiatan rumah tangga, termasuk istirahat, terganggu, terjadi juga peningkatan buangan limbah yang dihasilkan oleh kegiatan-kegiatan ekonomi rumah tangga, khususnya kerajinan dan pembuatan makanan. Kampung-kampung di - sepanjang sungai Winongo dimana terdapat konsentrasi industri rumah tangga tahu menimbulkan buangan limbah yang belum ditangani secara optimal.

\section{Ekspansi dari Luar}

Ekspansi dari luar baik untuk kegiatan komersial dan private juga menjadi penyebab berkurangnya ruang publik di kampung. Khususnya pada kampung-kampung yang 
Topik: Keterpaduan Sektor Formal dan Informal Perkotaan

mengalami proses upgrading, biasanya dijukti kemudian dengan proses-proses gentrifikasi karena ekspansi pihak luar kampung: Seperti ditunjukkan di perkampungan di sepanjang sungai Code, cukup banyak tanah warga kampung yang akhirnya dibeli oleh sektor private untuk pelebaran kegiatan usahanya, baik dalam bentuk toko ataupun usaha lain. Proses ini tentunya wajar, akan tetapi tetap harus diawasi dan dikritisi karena mengancam eksistensi kampung itu sendiri.

Ilustrasi Privatisasi dan Komersialisasi Ruang di Kampung

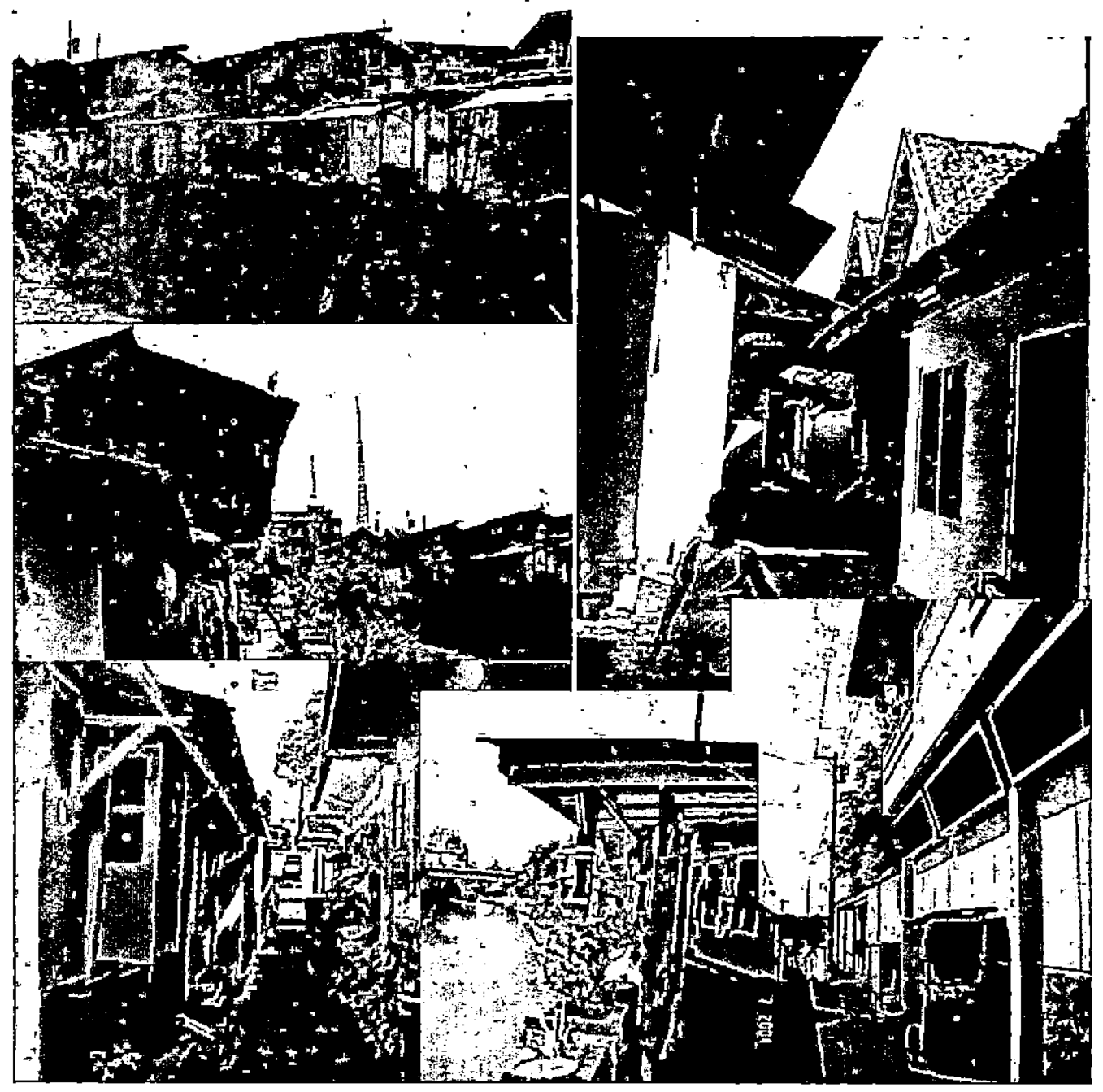




\section{Faktor-faktor yang Mempengaruh Proses Privatisasi dán Komodifikasi Ruang Publik di Kampung}

Terdapat páling tidak lima faktor yang berpengaruh terhadap proses privatisasi dan komodifikasi ruang publik di kampung. Pertama, keterbatasan dan aksesibilitas lahan. Sebagaimana diketahui, khususnya kota-kota di Jawa, mempunyai lahan yang terbatas. Dengan tingkat kepadatan penduduk rata-rata di pulau Jawa yang sangat-tinggi, sementara kebutuhan akan lahan-lahan untuk pertanian juga perlu dipertahankan; persoalan ketersediaan lahan merupakan persoalan besar kota-kota di pulaú Jawa. Persöalan ini diperparah dengan dua hal yakni inefisiensi pemanfaatan lahan dan spekulasi Jahan/ tanah. Inefisiensi ditunjukkan dengan model pengembangan kota yang sprawl dan boros lahn serta menimbulkan banyak lahan-lahan terlantar. Spekulasi lahan menyebabkan harga lahan meningkat dan semakin menyebabkan masyarakat miskin tidak dapä mengakses lahan bagi perumahannya. Akibatnya adalah proses pemadatan permukiman, khususnya di kampungkampung pusat kota, baik untuk kegiatan perumahan maupun untuk kegiatan komersial.

Kedua, ketidak jelasan pemilikan lahan. Meningkatnya kebutuhan akan lahan di perkotaan juga diperparah oleh situasi dimana banyak lahan-lahan di perkotaan Indonesia, termasuk di kampung kampung yang tidak jelas statusnya. Sebagaimana diketahui, ketidak jelasan status ini memicu proses pemantaatan lahan secara liar dan tak teratur. Khususnya di kampongkampung, dimana seringkali dibangun di kawasan-kawasan yang 'marginal' seperti di bantaran sungai, bekas pekuburan
Tionghoa; di sepanjang rel KA, status lahan/ tanah kawasan-kawasan ini memeang seringkali kabur. Sebagian tanah munkgin jelas kepemilikannya, tetapi sebagian lain tidak jelas, apakah milik pemerintah atauopun lembaga lain. Khusus di Yogyakarta, situasi ini diperparah dengan system pertanahan di Yogyakarta yang dualistic. pada mulanya, yakni gabungan anatar system kraton dan pemerintah formal RI. Dalam situasi ini banyak natah atau kawasan yang sampai sekarang masih belum jelas kepemilikannya, apakah milik kraton atau pemerintah. Lebih lanjut, dalam sistem ini pula terjadi apa yang disebut sebagai. 'ngindung' dan 'magersari' yang semakin menjadikan status tanah-tanh di kampong semakin rumit dan kompleks. Situasi ini memunginkan proses-proses privatisași dan kapitalasisasi ruang.

Ketiga, tekanan ekonomi terhadap penduduk/penghuni kampung juga memicu proses komersialisasi atau kapitalisasi ruang di kampung. Sebagaimana banyak dijelaskan dalam referensi, tekanan ekonomi terhadap keluarga miskin menyebabkan mereka berusaha memaksimalkan seluruh aset yang mereka punyai termasuk aset tanah/ruang. Upaya memaksimalkan pemanfaatan aset mereka ini ditujukan agar mereka survive. Ruang, baik ruang private maupun publik seringkali merupakan aset yang tersedia dan dapat dimanfaatkan sebagai strategi survival mereka.

Keempat, tekanan ekonomi yang memaksa warga kampung mengomersialkan dan memprivatisasikan ruang-ruang yang ada juga dipicu oleh kecenderungan melemahnya modal sosial, baik institusi, pranata, dan bahkan leadership dan jaringan warga kampung. Warga kampung cenderung bertindak secara individual untuk mencoba survive, dan individu-individu warga kampung juga tidak mempunyai waktu laung yang 
cukup untuk melakukan mobilisasi dana pengembangan jaringan sosial. Leadership di kampung jüga melemah karena secara individu pengurus warga kampung mungkin juga terjerat dalam tekanan ekonomi dan harus lebih meluangkan waktunya untuk survival strategi mereka sendiri (Setiawan 2000). Dengan kata lain, terjadi kecenderungan menurun dan melemahnya bentuk-bentuk kebersamaan warga kampung, yang kalau diteruskan akan mengancam dasar utama modal sosial yakni adanya 'trust' atau kepercayaan sesama warga kampung.

Kelima, absennya pedonian tata ruang dan tata bangunan kampung juga menyebabkan perkembangan kampung yang semakin tidak terkontrol. Ini tidak berarti bahwa perlu disusun rancangan atau pedoman pengembangan fisik kampung yang rinci, yang diperlukan adalah pedoman umum yang dapat memproteksi ruang-ruang publik yang esensial untuk warga kampung termasuk lebar gang yang cukup, taman dan tempat bermain, dan ruang hijau kampung.

\section{Penutup.}

Paper ini menekankan mengenai hubungan yang dialektik dan dinamik antara ruang dan kehidupan sosial. Ruang adalah hasil rekayasa manusia untuk mewadahi berbagai bentuk kehidupannya, sebaliknya ruang dapat menstimuli perilaku dan kehidupan sosial manusia. Kaitan yang dialektik dan dinamikini terjadi di lingkungan kampung, dan hal ini yang membuat kampung menjadi khas dan unik. Perencana dan arsitek harus semakin memahami pola hubungan yang dinamik dan dialektik ini agar ketika harus melakukan intervensi desain, intervensinya tidak justru mengganggu hubungan tersebut. Intervensi desain harus tetap memberikan ruang kebebasan bagi warga dan komunitas untuk terus berkreasi mensiasati hubungannya dengan ruang.

Tekanan penduduk dan ekonomi terhadap kampung.telah memaksa prosesproses privatisasi dan komersialisasi ruang di kampung, termasuk ruang publik. Proses privatisasi ini terjadi dalam berbagai bentuk, dan telah mengancam keberadaan ruang publik di kampung. Proses ini juga semakin membuat lingkungan kampung rentan terhadap berbagai masalah lingkungan baik ancaman kebakaran, limbah, pencemaran, over crowding.

Berkurangnya rụang publik ini mengurangi kesempatan dan kemungkinan warga untuk melakukan kegiatan-kegiatan sosial yang dapat memperkaya modal sosial warga. Ketiadaan ruang bermain untuk anakanak memaksa anak-anak mengurangi kontak sosialnya sesama anak. Ketiadaan ruang olah raga untuk remaja dan pemuda juga mengurangi kemungkinan mereka untuk memperkaya hubungan sosial mereka. Singkatnya, berkurangnya ruang publik di kampung mengurangi sifat dan karakter 'komunal' kampung.

Terjadi pelemahan modal sosial kampung, baik pada tataran institusi, pranata, leadership, jaringan, dan bahkan kepercayaan/trust. Tekanan ekonomi dan sosial semakin membuat warga kampung cenderung lebih memikirkan survival strategi mereka dan ini memperlemah tingkat partisipasi warga untuk membangun dan memperkaya modal sosial. Sementara itu leadrship kámpung juga tidak selalu dapat diharapkan, oleh karena pemimpin di kampung juga cenderung mengalami tekanan ekonomi yang memaksa mereka lebih mementingkan survival strategi mereka sendiri. Implikasinya adalah ketiadaan kontrol terhadap proses-proses privatisasi dan komersialisasi ruang kampung yang merugikan kepentingan publik. 
Dalam konteks ini diperlukan pendampingan-pendampingan dari pihak luar untuk memfasilitasi warga kampung membangun kembali modal sosialnya. Pendampingan ini dapat dilakukan dalam berbagai bentuk, akan tetapi harus peka dilakukan dan tidak distandärkan, karena tiap kampung mempunyai persoalan yang beragam. Perencana dan arsitek dapat pula melakukan pendampingan untuk membantu warga kampung mendapatkan kembali ruang-ruang publik mereka. Proses pendampingan harus hati-hati, agar tidak mengurangi inisiatip, kreasi, dan energi warga kampung dalam membentuk lingkungannya. Warga kampung hanus tetap diberi peluang dan ruang dan bahkan kemerdekaan untuk menentukan wujud kampungnya - hanya dengan ini kampung akan mungkin menjadi alternatip bentuk ruang kehidupan yang 'livable.'

\section{Daftar Pustaka}

Carmona Dkk. 2003. Public Places - Urban Spaces: The Dimensions of Urban Design. Boston: Architectural Press.

Castell, M. 1977. The Urban Question. London: Edward Amold.

Castell, M. 1978. City, Class, and Power. London: Macmillan.

Castell, M. 1983. The city and the Grassroots. London: Edward Arnold.

Dasgupta P. Dan Ismail Serageldin. 2000. Social Capital: A Multifaceted Perspective. The World Bank, Washington D.C.

Desai, V. 1995. Community Participation and Slum Housing, A Study of Bombay. New Delhi: Sage Publications.
Etzioni, Amitai. 1993. The Spirit of Community: The Reinvention of AmericanSociety. New York: A Touchstone Book.

Gilbert, A. and P. Waird. 1985. Housing, the State and the Poor: Policy and Practice in Three Latin American Cities. Cambridge: Cambridge University Press.

Guinnes, Patrick. 1986. Harmony and Hierarchy in a Javanese Kampung: Singapore: Oxford University Press.

Harrison, David. 1988. The Sociology of Modemization and Development. London: Unwin Hyman.

Haryadi. 1989. Residents's Strategies for Coping with Environmental Pressures: Relation to House-Settlement Systems in a Yogyakarta Kampung, Indonesia. PhD. Dissertation: The University of Wiscounsin-Milwaukee.

Harvey, David. 1989. The Condition of Postmodernity. - Oxford: Basil Blackwell.

Indarto. 1995. Jalan Rukunan di Yogyakarta. Tesis S2 Arsitektur Universitas Gadjah Mada.

Lesser, Eric. 2000. Knowledge and Social Capital: Foundations and Applications. Boston: Butterworth Heinemann.

Nareswari. 1996. Proses Perubahan Ruang dan Kegiatan di Kampung Ratmakan. Tesis S2 Arsitektur, Universitas Gadjah Mada. 
Topik: Keterpaduan Sektor Formal dan Informal Perkotaan

Nelson, J.M. 1979. Access to Power. Politics and the Urban Poor in Developing Nations. Princeton, New Jersey: Princeton University Press.

N'Dow, Wally. 1996. “The Future of Cities Lies in Istanbul." In Habitat Publications, UNCHS, May 1996.

Parker, s. 2004. Urban Theory and the Urban Experiences. London dan New York: Routledge.

Rapoport, A. 1969. House Form and Culture. New York: Prentice Hall Inc.

Rapoport, A. 1977. Human Aspects of Urban Form. Oxford: Pergamon Press.

Rapoport, A. 1982. The Meaning of the Built Environment. Beveriy Hills Califomia: Sage Publications.

Roseland, M. 1998. Toward Sustainable Communities: Resources for Citizens and Their Governments. Canada: New Society Publisher

Saunders, P. 1986. Social Theory and the Urban Question. London: Hutchinson.

Schulz, A. 1979. Local Politics and nationstates, Case Studies in Politics and Policy. Santa Barbara, Califomia: Clio Books.
Setiawan, B. Dkk. 1987. Code River Settlement: Preliminary Study on the Community's Potential in Settlement Upgrading. Intemal publikasi. Jurusan Teknik Arsitektur UGM.

Setiawan, B. 1993. "Hosuing Delivery System in the Code River." Dalam Jumal Perencanaan Wilayah dan Kota ITB.

Setiawan, B. 1995. Community development model: lessons from four kampungs along the Code River, Yogyakarta. Paper presented at the workshop on the Study of Community Development in the Code River Basin, Yogyakarta, 16 May.

Setiawan, B. 1998. Local Dynamics in Informal Settlement Development: $A$ Case Study of Yogyakarta, Indonesia. PhD. Dissertation, The University of British Columbia, Canada.

Sullivan J. 1992. Local Government and Community in Java: an urban case study. Singapore: Oxford University Press.

Zaim, Z. 2004. Perubahan Pemanfaatan Ruang Kawasan Perumahan Tepian Sungai: Studi Kasus Ruas Sungai Code Kota Yogyakarta. Tesis S2 Arsitektur UGM. 